\title{
Historical Narratives of the Kangxi Emperor's Inaugural Visit to Suzhou, 1684
}

\author{
Michael G. Chang
}

\section{Introduction}

Almost every student of the Qing dynasty (1644-1911) and of Chinese history more generally is familiar with the 'southern tours' of the Kangxi and Qianlong emperors. ${ }^{1}$ These were political spectacles of the first order which facilitated the consolidation of Qing rule in China proper and spawned a number of narrative accounts. ${ }^{2}$ The purpose of this essay is to recapture the dynamic negotiations between various historical actors that were inherent to the consolidation of Qing rule. In particular, it focuses on knowledge production and the writing of historical narratives as both a mode and a means of political participation and negotiation.

The Kangxi emperor's inaugural southern tour was a relatively short affair, lasting only sixty days from early November through December of $1684 .{ }^{3}$ During this time, the emperor engaged in a wide range of endeavours. In Shandong province, he performed sacrifices at the sacred peak of Mount Tai and paid homage to the Confucian Temple in Qufu. In northern Jiangsu province, he inspected critical hydraulic infrastructure and 'inquired about the people's hardships.' Once south of the Yangtze River, the Kangxi emperor 'observed local customs' particularly in the prosperous city of Suzhou, the southernmost point on the imperial itinerary in 1684 (fig. 1).

1 The Kangxi emperor (Aisin Gioro Xuanye; 1654-1722, r. 1661-1722) embarked on six southern tours in 1684, 1689, 1699, 1703, 1705, and 1707. His grandson, the Qianlong emperor (Aisin Gioro Hungli; 1711-1799, r. 1736-1795) also embarked on six southern tours in 1751, 1757, 1762, 1765, 1780, and 1784. For more on the former see Jonathan D. Spence, Ts'ao Yin and the K'anghsi Emperor, Bondservant and Master (New Haven, 1966), 124-57; for more on the latter see Michael G. Chang, A Court on Horseback: Imperial Touring and the Construction of Qing Rule, 1680-1785 (Cambridge, MA, 2007).

2 The southern tours were highly publicised undertakings, celebrated at the time in vast official compendia, outpourings of courtly verse, monumental court paintings, and more recently, in serialised television dramas.

3 On average, each of the Kangxi emperor's six southern tours lasted about three months $(86.7$ days). Chang, A Court on Horseback, 116. 
These activities form a central part of the historical record, and the Kangxi emperor and his officials repeatedly cited them as justifications for his first (and subsequent) southern tour(s). As documented in official sources, the southern tours fit squarely within a venerable tradition of Confucian rule and statecraft which emphasised, and indeed demanded, the emperor's 'reverence for Heaven' (jing tian), his 'administrative diligence' (qin zheng), and his 'cherishing of the people' (ai min).

In ideological terms, such phrasing alluded to the rule of ancient sage-kings, as recorded in the classical texts of Chinese political philosophy. Modern scholars have cited this rhetorical accommodation of Confucian values, ideals, and expectations as evidence of the Qing court's 'sinicisation', 'acculturation', and more recently, its 'continuation of ruling orthodoxy and political identity.' However, as suggested elsewhere and reiterated below, the Kangxi emperor's southern tours were not simply one-way exercises in cultural or political accommodation, nor should they be treated as such. ${ }^{5}$

A close and careful reading of available sources reveals that the meaning and significance of the Kangxi emperor's first southern tour of 1684 were neither self-evident nor agreed upon. The Kangxi emperor's first visit to Suzhou in late 1684 was a momentous 'event', the precise meaning of which was always open to interpretation by a range of historical actors, both at court and beyond. ${ }^{6}$ These historical actors produced narrative accounts which sometimes overlapped, but not always and never completely. Equally important, these narratives functioned not as reflections of an a priori reality, but rather as discursive

4 Chang Jianhua, 'Xin jiyuan: Kangxi di shouci nanxun qiyin Taishan xunshou shuo' [Beginning of a New Era: the Justification of the Kangxi Emperor's First Southern Tour as an Eastern Tour to Taishan], Wenshizhe 2 (2010); and idem, 'Guojia rentong: Qingshi yanjiu de xin shijiao' [National identity: a new perspective on the study of Qing history], in Liu Fengyun, Dong Jianzhong, and Liu Wenpeng, eds, Qingdai zhengzhi yu guojia rentong [Qing dynasty politics and national identity] (Beijing, 2012), 35-61.

5 Michael G. Chang, 'Kangxi's Southern Tours: A Historical Reconsideration', in Reign of the Kangxi Emperor: Conference Proceedings (Singapore, 2010), 20-35; and 'On Civil-Military Tensions during the Kangxi Emperor's First Southern Tour', Frontiers of History in China 6, no. 1 (March 2011), 26-52.

6 The analysis here builds upon the ideas of Marshall Sahlins who argues that 'an event is not simply a phenomenal happening ... apart from any given symbolic scheme. An event becomes such as it is interpreted. Only as it is appropriated in and through the cultural scheme does it acquire an historical significance' (xiv). In more succinct terms, 'The event is a happening interpreted-and interpretations vary.' Marshall Sahlins, Islands of History (Chicago, 1985), 153 . 


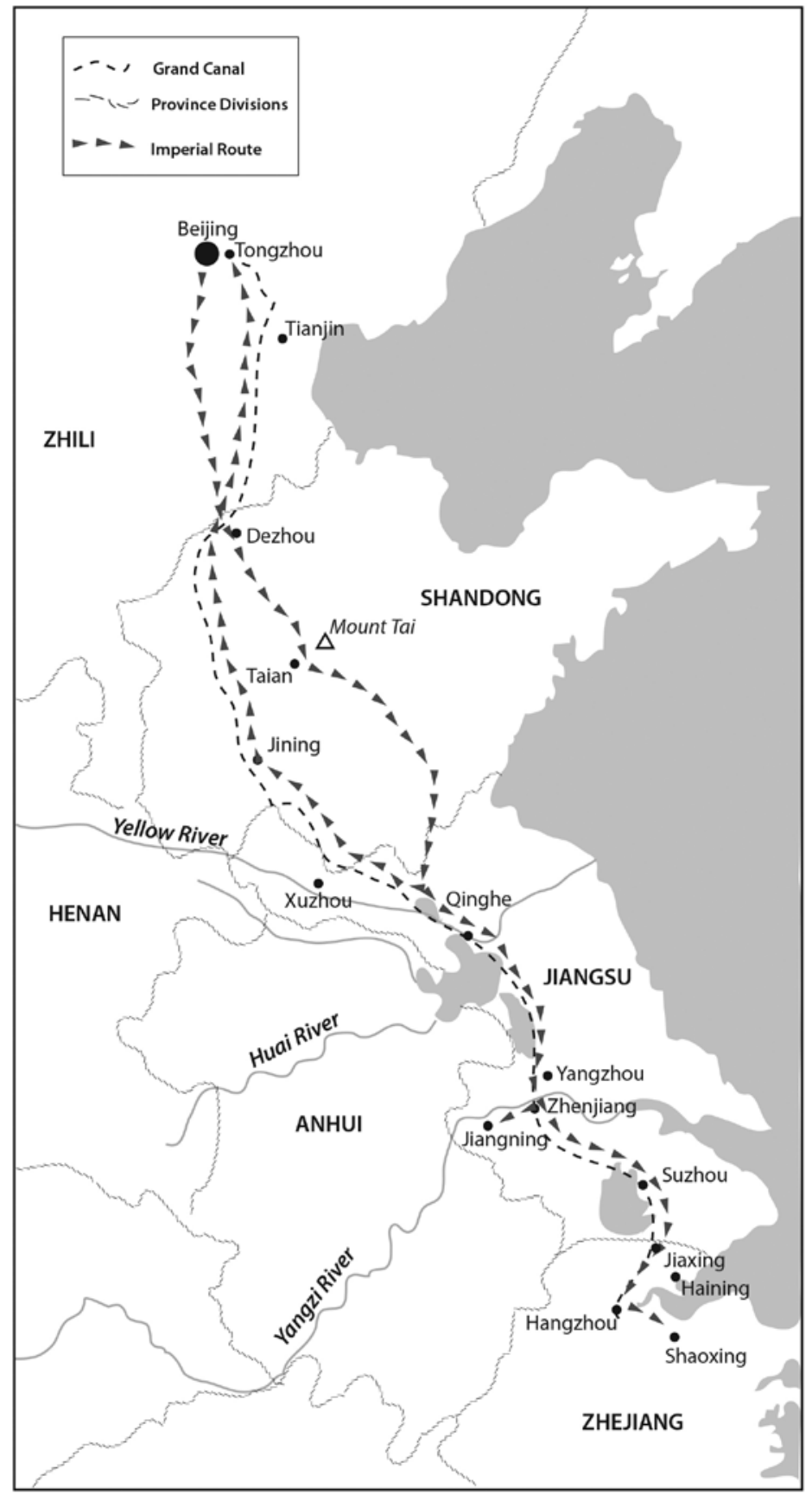

FIGURE 1 Map of the Kangxi emperor's southern tours. 
claims to knowledge about the imperial court and, by extension, about the meaning and nature of Qing rule.

The prospect of an imperial visit to Suzhou in late 1684 was a delicate matter for at least two reasons. First there was popular sentiment, particularly as it related to the specific timing of the trip. Qing forces had only recently quelled the rebellion of the Three Feudatories (1673-1681) and scored decisive victories over the maritime forces of the Zheng family based in Taiwan, in December 1681 and in October 1683 respectively. Expressions of lingering anti-Manchu sentiment and/or local discontent during an imperial visit might embarrass the emperor and his officials. A second issue was the reputation of Suzhou in particular, and of the Lower Yangtze region more generally, as a centre of economic prosperity and cultural refinement as well as of luxuriant and leisurely lifestyles. This posed the problem of what attitude the Kangxi emperor should assume in relationship to his immediate surroundings while on tour. The authors of the narrative accounts discussed below were all keenly aware that the portrayal of the Kangxi emperor's disposition towards Suzhou and its inhabitants was a matter of great symbolic and political significance.

\section{Court Narratives}

Two court sources— the Imperial Diaries (Qijuzhu) ${ }^{7}$ and an imperial essay entitled 'Notes on a Southern Tour' (Nanxun biji) ${ }^{8}$ - complement each other and together form the court's official account of the Kangxi emperor's first visit to Suzhou in 1684 . The Imperial Diaries is a daily and contemporaneous record of the emperor's public activities, including his movements and speech. ${ }^{9}$ As a contemporaneously composed record that was intended to provide raw data for the posthumous compilation of the so-called Veritable Records for each

7 Zhongguo diyi lishi dang'anguan, comp., Kangxi qüuzhu [The Kangxi Era Imperial Diaries] (Beijing, 1984) [hereafter cited as KXQJZ], 1244-1245.

8 Qing Shengzu [The Kangxi Emperor], 'Nanxun biji' [Notes on a Southern Tour] in Kangxi di yuzhi wenji [Collected Writings of the Kangxi Emperor] (Taibei, 1966) [hereafter cited as KXYZWJ], 316-321.

9 The establishment of the Office of the Imperial Diaries in 1671 was in fact intended to mollify Chinese officials who had objected to (and effectively stymied) the Kangxi emperor's initial attempt to embark on a patrol of northern border regions in late 1668. This fact alone indicated that the king's body and dispositions - his actions and movements, his active speech and writing, his conduct and comportment—were points of intense ideological interest and contention. 


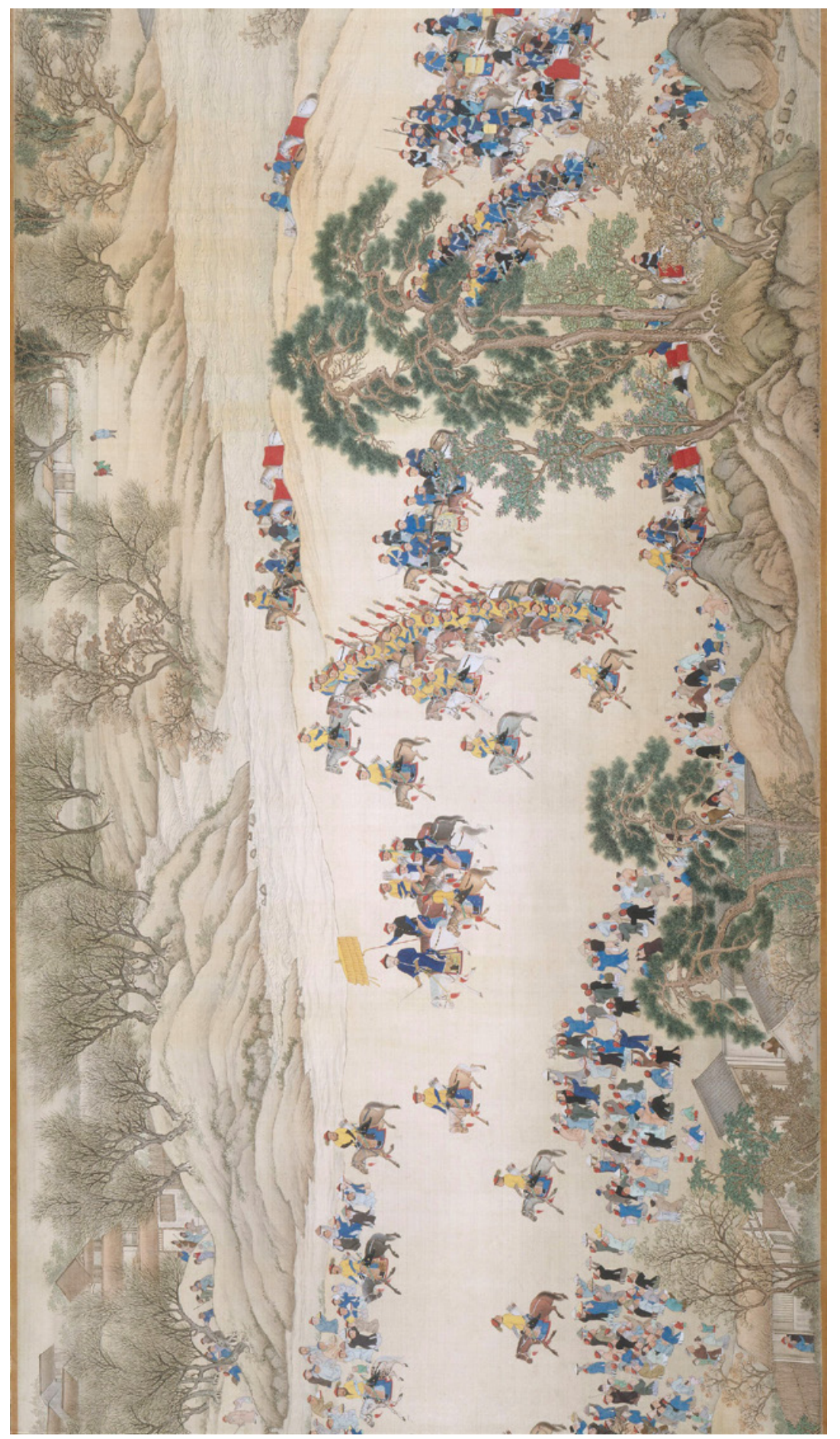

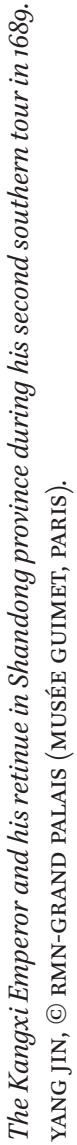

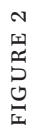


emperor's reign, ${ }^{10}$ the Imperial Diaries would have been read and circulated only among a privileged group of courtiers and official historians. Besides providing a daily record upon which later court histories might be based, the imperial diarists were also preoccupied with the task of imperial legitimisation which entailed the discursive production of a properly 'ritualised body' of a sage-king." ${ }^{11}$ This broader agenda directly informed the diarists' decision to restrict their coverage of the first imperial visit to Suzhou to two emblematic scenes of the emperor's arrival and departure.

As recorded in the Imperial Diaries, the imperial procession arrived in Suzhou on 2 December 1684. In their entry for this day, the imperial diarists painted a portrait of a diligent and compassionate monarch who tended to matters of local administration by meeting with local civil and military officials and who showed his empathy for porters, boat trackers, and members of the imperial guard, all of whom had provided security and logistical support during the imperial procession's swift, but arduous, overnight journey from Danyang to Suzhou (a distance of over $190 \mathrm{~km}) .{ }^{12}$ In the next day's entry, the imperial diarists described how the imperial procession immediately departed the city proper and visited Tiger Hill, located in Suzhou's north-western suburbs, about four kilometres outside the city wall. ${ }^{13}$ Here they directly quoted the Kangxi emperor, who turned to an unnamed official ${ }^{14}$ and said:

Previously [We] had heard that the Chang Gate [district] of Suzhou is prosperous. ${ }^{15}$ Now seeing its social customs, in general they [merely] valorise empty ostentation and leisurely ease. Those who engage in com-

10 Feng Erkang, Qingshi shiliao xue [Study of Qing historical documents] (Taibei, 1993), 34-44; and Qiao Zhizhong, Qingchao ganfang shixue yanjiu [Research on official historiography in the Qing dynasty] (Taibei, 1994), 159-176. In fact, the account of the Kangxi emperor's first visit to Suzhou found in the Veritable Records of the Kangxi period (published in 1731) closely follows that of the Imperial Diaries.

11 Angela Zito refers to this inextricable intertwining of 'ritualization' and knowledge production as 'text/performance.' Angela Zito, Of Body \& Brush (Chicago, 1997), 51-64.

$12 \quad \mathrm{KXQJZ}, 1244-1245$.

13 For more on Suzhou's suburbs, commercial districts, and markets during the Ming period (1368-1644) see Michael Marme, Suzhou: Where the Goods of All Provinces Converge (Stanford, 2005), 29-39.

14 According to Zhao Erxun et al., Qingshi gao [Draft History of the Qing Dynasty] (Beijing, 1998) [hereafter cited as $Q S G$ ], the Kangxi emperor made this remark to Tang Bin, who was then serving as the provincial governor of Jiangsu. QSG, 9930.

15 One of Suzhou's six main gates in the Ming-Qing period, Chang Gate was located in the north-western sector of the city, on the western part of the city wall, and was a focal point 
merce are legion, while those who till the fields are few, all of which results in lavish and wealthy households, but also superficial and duplicitous social relations. Those serving as local officials should encourage the elimination of extravagance and a return to simplicity. All attention and energy should be devoted to agriculture, only then will each household have sufficient means and the decadent mood be reversed. Then gradually after some time, there will be happiness and harmony. ${ }^{16}$

The inclusion of this pronouncement conveyed that the Kangxi emperor was visiting Suzhou simply to 'observe local customs' and that he preferred the time-honoured virtues of farming and frugality to the urban attractions of commerce and conspicuous consumption.

This rendering of the Kangxi emperor's first visit to Suzhou was certainly meant to bolster his image as a hard-working, compassionate, and frugal ruler, but it was also quite abbreviated. Its narrative structure tends towards temporal compression and social distancing. By starting their account with a rather vague statement that 'His Majesty spent the night inside Suzhou's city wall', the imperial diarists effectively truncated the narrative and insulated the ruler from the city. It was as if the emperor arrived, went immediately to his temporary quarters (where he received local officials and rewarded members of his retinue), and then quickly departed the next day, but not before registering his disapproval of the city's extravagant and ostentatious ways. Here the imperial diarists sought to show that the imperial procession did not linger in Suzhou and that the emperor's overarching concern was to keep local officials focused on improving local customs. Indeed, the Kangxi emperor's brief one-night stay in Suzhou along with his hurried pace while travelling south of the Yangtze River were presented as further manifestations of this imperial attitude and disposition. This rather dispassionate public image was well suited for a court chronicle, but might also impart a certain aloofness or even disdain on the part of the throne, which might have, in turn, risked offending Suzhou's local elites, a number of whom had served at the Kangxi court in the early 1680 s. $^{17}$

of Suzhou's vibrant commercial district which extended to Tiger Hill in the north-western suburbs.

$16 \quad K X Q J Z, 1245$.

17 Indeed, Wang Wan, one of Suzhou's best-known scholars had served in the Hanlin Academy from 1679-1682 and led a group of retired officials, including seven other former Hanlin Academicians, to greet the imperial procession at the Hushu Customs House, about $25 \mathrm{~km}$ northwest of Suzhou proper. Feng Guifen et al., Suzhou fuzhi [Gazetteer of Suzhou Prefecture, c. 1883] (reprint Taibei, 1970), juanshou, 1a. 
This last dilemma may explain the composition of an imperial essay entitled 'Notes on a Southern Tour.' Authorship of this piece is attributed to the Kangxi emperor, and it employs the first-person pronoun 'zhen' 朕 which was reserved exclusively for imperial use. However, the essay was in all likelihood revised and edited, if not entirely ghost-written, by the emperor's personal secretary Gao Shiqi $\left(1645^{-1703}\right)^{18}$ shortly after the imperial procession's return to Beijing in early January $1685 \cdot^{19}$

In 'Notes on a Southern Tour' the emperor appears to be more open and actively engaged with Suzhou and its residents. Where the imperial diarists offered only allegorical snapshots, the author(s) of this imperial essay produced a slightly more developed narrative account punctuated by scenes of popular acclamation. Foremost among these was the imperial rite of entry, which drew a large and enthusiastic crowd:

On the twenty-seventh day [3 December 1684] [His Majesty] entered Chang Gate via Maple Bridge ${ }^{20}$ and climbed the city wall to get a better view of local scholars and commoners. Everybody was dancing and waving, and some presented laudatory poems. ${ }^{21}$

In addition to taking in such expressions of popular sentiment, the emperor also seemed more willing to partake of Suzhou's material abundance and renowned scenery. For instance, he apparently deemed Suzhou's local produce

18 Arthur W. Hummel, Eminent Chinese of the Ch'ing Period (Washington, DC, 1943-44; reprint Taibei, 1991) [hereafter cited as ECCP], 413-414. Gao entered the Kangxi court in 1671 and served as an imperial companion throughout the 1670s. He accompanied the Kangxi emperor on his numerous imperial tours in the early 1680 s, including this first southern tour.

19 The Kangxi emperor's collected writings appeared in four 'parts', and those from the first southern tour of 1684 appear at the very end of 'part one'. (The last imperial edict included in part one was addressed to local officials in Jiangnan and dated 9 December 1684, while the first imperial edict in part two was addressed to metropolitan officials and dated 4 January 1685 , just one day after the imperial procession's return to Beijing.) This internal arrangement of material suggests that the first southern tour of 1684 was a major turning point and that the court hoped to promulgate its own account of these events sooner rather than later. Zhu Saihong, comp., Qingdai yuzhi shiwen pianmu tongyan [Comprehensive index to imperial poetry and prose of the Qing dynasty] (Beijing, 2007), 5,8 , and 10 .

20 Maple Bridge (Fengqiao) was the best known of Suzhou's 390 bridges and was located about $5 \mathrm{~km}$ outside of (to the west of) Chang Gate. Shi Weile, Zhongguo lidai diming da cidian (Beijing, 2005), 1499.

$21 \quad$ KXYZWJ, 319. 
worthy of being used as a form of imperial largesse: 'On this day [We] spent the night in the city. Considering that the service personnel [porters, boat trackers, etc.] had toiled over such a great distance, [We] bestowed silver upon all and allowed each to take some local products as an expression of [Our] solicitude.'22 Additional and more detailed descriptions of imperial visits to well-known sites and scenic vistas at Tiger Hill stood as further evidence of the emperor's cultural curiosity and receptiveness. ${ }^{23}$ Finally, 'Notes on a Southern Tour' even detailed how, on the day of his departure from Suzhou, the Kangxi emperor continued his regular habit of spending two to three hours every evening composing poetry, reading and discussing classical and literary texts, and considering the rise and fall of ancient and more recent dynasties with the imperial favourite and travelling companion Gao Shiqi. ${ }^{24}$ Given its generic form and its specific contents, 'Notes on a Southern Tour' was clearly aimed at promoting a more scholarly and culturally conciliatory imperial image that might appeal to the region's men of culture and learning.

Such expressions of imperial openness to literati culture and learning as well as to Suzhou's scenic beauty, however, were always offset by more critical assessments. For instance, after detailing his daily studies with Gao Shiqi, the Kangxi emperor remarked, 'The meanings of the Classics are indeed profound, [but] not as good as [one's own] ears and eyes, and it is easy to grow tired of them.'25 In similar fashion, the emperor's appreciative descriptions of Tiger Hill's scenic sites were counterbalanced with more negative comments about the highly commercialised and ostentatious social milieu just outside the temple's main gate. However, instead of exhorting local officials to 'eliminate extravagance and return to simplicity', as he had done in the Imperial Diaries, in 'Notes on a Southern Tour' the Kangxi emperor simply declared that 'the vain pursuit of extravagant luxury in obliviousness to agriculture cannot compare to the simple and honest customs of the northeast. ${ }^{26}$ Here the emperor was no longer preoccupied with the administrative diligence of local and regional officials, nor the improvement of local customs, but rather with making a regional (and implicitly ethnic) comparison between the prosperous but extravagant southeast (Jiangnan) and the simple but frugal northeast (Manchuria).

\footnotetext{
$22 \quad K X Y Z W J, 319$ (emphasis added).

23 The sites visited included 'Thousand Person Stone Terrace' (Qianren shi), 'Nodding Head Rock' (Diantou shi), 'Sword Pond' (Jian chi), and Pingyuan Pavilion (Pingyuan tang).

$24 \quad K X Y Z W J, 319$.

$25 \quad K X Y Z W J, 319$.

$26 \quad K X Y Z W J, 319$.
} 
The Kangxi emperor (and/or his imperial ghost-writers) might exhibit curiosity about, or even an appreciation of, China's textual tradition as well as Suzhou's local products, scenery, and customs. However, as a Manchu monarch who hailed from the 'simple and honest' northeast, he was compelled to maintain a certain degree of distance. Not surprisingly, the Kangxi emperor was quick to disavow Suzhou's lifestyle of luxurious ease, especially the practice of leisurely sightseeing:

On this trip... [Our] first daily duty was to inquire about the people's hidden [hardships] and to check on local administration. In [spare] moments on the road, We might also view the local scenery and visit historic sites. [...] We have taken up a brush and recorded this in order to convey that We do not vainly embark upon leisurely pleasure tours. ${ }^{27}$

The Qing court, then, strove to balance demands of cultural accommodation, on the one hand, with the equally pressing requirements of maintaining dynastic authority through gestures of disavowal and distancing on the other. As such, court accounts of the Kangxi emperor's first visit to Suzhou are marked not only by symbolic displays of administrative diligence, imperial benevolence, and even cultural receptiveness; but also by expressions of social and cultural distancing.

\section{Local Narratives}

In contrast to the court sources discussed above, local narratives provide more detail about the Kangxi emperor's activities within Suzhou proper. Take, for example, the 'Record of an Imperial Visit' (Xunxing jishi) which was written by the local magistrate of Wu county, Liu Zi, ${ }^{28}$ and included in the 1691 edition of the Wu County Gazetteer. ${ }^{29}$ This local account details the Kangxi emperor's

$27 \quad$ KXYZWJ, 321.

28 Liu Zi was a native of Ren county in Zhili province, who earned his metropolitan (jinshi) degree in 1661. He served as the magistrate of Wu county from March 1683 until 1686, when he was appointed to an official post in the capital. Magistrate Liu's entry into the metropolitan bureaucracy came at the behest of his superior, Jiangsu Provincial Governor Tang Bin, who recommended him for promotion in 1685. Sun Ming'an et al., comp., Wuxian zhi [Wu County Gazetteer, c. 1691] (reprint Yangzhou, 1989) [hereafter cited as WXZ ], juan 2, 37a-b and juan 41, 15a; as well as $Q S G, 9932$.

$29 W X Z$, juan shou, 1a-6b. Wu county was located in Suzhou prefecture. 
face-to-face interactions with local denizens inside the city wall and situates these episodes within a broader framework of the ruler's taking symbolic possession of Suzhou. By oscillating between imperial assertions of symbolic dominion over the city, on the one hand, and gestures of cautious conciliation with local residents, on the other, Magistrate Liu conveys a more dynamic sense of imperial engagement and interaction with the local populace, which is largely absent from the court sources discussed earlier.

According to Magistrate Liu, upon its arrival the imperial procession 'proceeded to Suzhou's western suburbs, [where] His Majesty mounted a horse and entered Chang Gate.' However, before doing so, 'His Highness ordered that pedestrians not be kept away [from the imperial procession] and that marketplaces carry on business as usual.' As a result, 'scholars and commoners all responded cheerfully by setting up [altars for burning] incense and candles, and knelt along the left side of the roadway to greet [the emperor].'30

This record of events suggests that both the Kangxi emperor and local officials were quite conscious of the symbolic import of this moment and sought to stage-manage the imperial rite of entry. The emperor's decision to enter the city on horseback may have stemmed from a desire not only to better see and be seen, but also to be seen as a symbolic conqueror. Here the sight of a Manchu ruler entering the city on horseback via Chang Gate, which was historically associated with military expeditions, ${ }^{31}$ would have presumably heightened the overall effect.

Interestingly enough, neither of the official court sources discussed above mention the Kangxi emperor's entry into Suzhou on horseback. This discrepancy between court and local sources may indicate that local officials were perhaps more willing (or even obliged) to acknowledge the emperor's status as a triumphant ruler on horseback. As a corollary, literati courtiers may have been less inclined (or obliged) to incorporate such a highly charged and martially inflected scene into their accounts. In any case, official knowledge production at the local level seems to have required (or allowed for) a slightly different portrayal of the Kangxi emperor entering the city on horseback.

\footnotetext{
$30 \quad$ wXZ, juan shou, 2b-3a.

31 According to a late Tang (eighth or ninth century) source, Chang Gate was also known as 'Destroying Chu Gate' ( the early Warring States period ( $475^{-256}$ BCE), troops from the Kingdom of Wu (based in Suzhou) set out from Chang Gate in 506 вСE to attack the neighbouring Kingdom of Chu and victoriously re-entered the city at the same place in 505 BCE. Lu Guanghui, Wudi ji [Record of Suzhou Place Names] (Nanjing, 1999), 17.
} 
Of course, the visual impact of this imperial rite of entry depended on having an audience, which may explain why the Kangxi emperor ordered local officials to refrain from keeping ordinary residents away and to make sure that local markets remained open. The promulgation of this imperial edict may have also been in response to overly cautious officials who wanted to orchestrate and control every detail of the imperial visit. ${ }^{32}$ Unexpected mishaps or occurrences were bound to reflect poorly on local administration, which may have informed Magistrate Liu's decision to describe the general mood not as one of spontaneous acclamation or unbridled reverie on the part of the joyous masses, but rather that of quiet reverence and respect expressed by enthusiastic yet orderly subjects.

If the imperial rite of entry was an act of symbolic conquest, the Kangxi emperor's encounter with an elderly bystander symbolised local acceptance of Qing rule. According to Magistrate Liu's account, 'His Majesty halted [the procession] upon encountering a white-haired [man] with a cane, whom [He] summoned forward.' The emperor, as Magistrate Liu noted, then 'personally inquired about [the man's] age and whether he had any descendants and then politely refused [the man's] offering of fruit and cakes [as local tribute]. ${ }^{33}$ Official accounts of later tours herald the presence of elderly commoners as an emblem of a peaceful and prosperous age. Such individuals usually received rewards in recognition of their longevity, and their ages were publicised (usually eighty, ninety, or even one hundred sui-the older the better). The 'whitehaired man' whom the Kangxi emperor encountered in Suzhou in 1684 was clearly advanced in years, but (judging from his cane) was also somewhat frail, or at least not in the best physical condition. Moreover, Magistrate Liu recorded neither the man's exact age nor how many descendants he might have-two key indicators of a healthy and prosperous life. Assuming this white-haired man was in his fifties at the time, he would have been a child or a young adult in the 1640 s and 1650 s and would have witnessed first-hand the wars of dynastic transition. All of this suggests that the appearance of this elderly subject was not necessarily intended as a sign of peace and prosperity, but rather as a tableau vivant of Suzhou's submission to Qing rule, hence the presentation of local tribute.

Magistrate Liu's descriptions of the Kangxi emperor's dealings with Suzhou's Buddhist clergy also capture the locally negotiated aspects of Qing rule. Immediately after his encounter with the elderly resident, the Kangxi emperor visthe assembly of commoners to welcome the imperial procession. KXQJZ, 1245 . 
ited Ruiguang Temple in the south-western corner of the city. After entering the temple's main gate, the emperor 'asked the abbot Jie Xuan [about his] sectarian affiliation, and [Jie] Xuan kowtowed and answered. ${ }^{34}$ Magistrate Liu's account of this exchange ends rather abruptly without revealing the abbot's religious leanings. The meaning of this episode is more readily apparent when compared to the description of an imperial audience with another monk which took place at Tiger Hill on the following day:

On the jiwei day [3 December 1684], the imperial procession set out from Chang Gate and visited Tiger Hill [where] the monk Yuanshi [literally 'original era'] knelt and greeted [the emperor].

His Majesty asked, 'What sect are you?'

[Yuan]shi answered, 'The Linji [sect of Chan Buddhism].'

[His Majesty] bestowed upon [Yuanshi] a new name of 'Chaoshi' [literally 'transcending eras']. ${ }^{35}$

Here the monk's reply was apparently to the throne's liking and thus warranted both inclusion in the written record and the bestowal of a new name by the emperor. By juxtaposing these imperial meetings with two different members of Suzhou's Buddhist clergy, Magistrate Liu was perhaps sending a message to members of the local samgha and their lay patrons: one's sectarian affiliations and theological inclinations mattered to the Qing court. Exactly how and why one's religious orientation may have mattered deserves further study. ${ }^{36}$ For now, we may simply note that Magistrate Liu's account reflected the willingness of local officials to at least acknowledge and record the court's ongoing (and ostensibly successful) efforts at winning the hearts and minds of Suzhou's broader populace.

$34 \quad W X Z$, juan shou, 3 a.

$35 W X Z$, juan shou, 3 a.

36 This may have been related in some way to the fact that many Han Chinese literati who harboured anti-Manchu sentiments or who simply feared for their safety under the new regime opted to take the tonsure during the wars of dynastic transition and fled to nearby Buddhist monasteries, many of which continued to provide refuge for such disaffected individuals into the 1680s. Perhaps the most prominent example of this phenomenon was Zhu Da (aka Bada Shanren; 1626-1705), the early Qing 'individualist' master and descendent of the Ming royal house who first found sanctuary in a Buddhist temple in 1648 and did not return to secular life until 1680. Joseph Chang, 'The Life and Painting of Bada Shanren', in idem, In pursuit of heavenly harmony: paintings and calligraphy by Bada Shanren from the Estate of Wang Fangyu and Sum Wai (Washington DC, 2003), 1-10. 
This endeavour to broker a modus vivendi with Suzhou's local residents, however, was always framed by more assertive gestures of imperial authority. For instance, after describing the Kangxi emperor's visit to Ruiguang Temple, Magistrate Liu continued:

[His Majesty] passed through Pan Gate [at the western end of Suzhou's southern wall] and mounted the city wall [in order to] survey the surrounding ramparts and battlements. [He] descended at Qi Gate [at the eastern end of Suzhou's northern wall] and visited the Garden of the Humble Administrator. [He then] reached Feng Gate [at the southern end of Suzhou's eastern wall] via Lindun Road and spent the night at the Silk Commissioner's residence. ${ }^{37}$

As we may recall, the imperial essay 'Notes on a Southern Tour' also described how the Kangxi emperor 'climbed the city wall', in order 'to get a better view of local scholars and commoners. ${ }^{38}$ However, in the local gazetteer Magistrate Liu depicted the emperor's mounting of Suzhou's city wall as a martially inflected effort to 'survey the surrounding ramparts and battlements' that would have also included inspecting the surrounding terrain while circling from Pan Gate in the southwest to Qi Gate in the northeast. This circumambulation of Suzhou's city wall was a demonstration of imperial domination and reflected the mind-set of a military strategist, which was also on full display during the emperor's visit to the provincial capital of Jiangning just four days later (7 December 1684). ${ }^{39}$

In terms of describing the Kangxi emperor's first visit to Suzhou, Magistrate Liu's 'Record of an Imperial Visit' in the Wu County Gazetteer is lengthier and more detailed than official court sources. However, it is still very much an 'official' account, produced under the auspices of regional and local officials who sought to enhance their own standings and reputations both at court and in

$37 \quad$ WXZ, juan shou, 3 a.

$38 \quad$ KXYZWJ, 319 .

39 While in Jiangning (present-day Nanjing) the Kangxi emperor composed an imperial essay in which he assessed the former Ming capital's natural defences. The title of this essay was 'On Passing through Jinling' (Guo Jinling lun), and the relevant passage reads, 'Although Jinling [Jiangning] has the advantage of the Yangtze River as Heaven's Moat, its terrain is weak, possessing nothing on which it can depend.' $K X Q J Z, 1247$; and Jonathan Hay, 'Ming Palace and Tomb in Early Qing Jiangning: Dynastic Memory and the Openness of History', Late Imperial China 20, no. 1 (1999), 17-19. 
the provinces by informing local residents and observers about the negotiated but ultimately legitimate nature of Qing rule in Suzhou.

At least one local observer, a native of nearby Shanghai named Yao Tinglin (b. 1628), ${ }^{40}$ seems to have been familiar with this official perspective, but he did not necessarily agree with it. On the contrary, Yao produced an unofficial account that implicitly undermined the official portrayal of the Kangxi emperor's first visit to Suzhou. This counter-narrative appears in Yao's 'Record of Bygone Years' (Linian ji), a draft manuscript that is partly a memoir of daily life and partly a contemporaneous record of significant events in the lower Yangtze delta during the late seventeenth century. ${ }^{41}$ 'Record of Bygone Years' begins with Yao's birth in 1628; however, judging from internal evidence Yao began writing only in 1668 at the age of forty and continued to work on the text over the next three decades through $1697 \cdot^{42}$

In Yao's description of the first imperial visit to Suzhou, the Kangxi emperor appears as a savvy and politically astute Manchu ruler, who is mindful of the political implications of his every movement and gesture, but who cannot help but indulge himself in performances of local opera and popular music. In addition, Yao presents local officials—namely, Jiangsu Provincial Governor Tang Bin (1627-1687) ${ }^{43}$ and the Suzhou Silk Commissioner-as being engaged in a rather sycophantic competition for imperial recognition and favour, usually at the expense and to the detriment of the local community.

40 Yao Tinglin belonged to a once prominent but declining lineage based in Shanghai district (Songjiang prefecture). He was in his teens and twenties during the wars of dynastic transition and witnessed the ruination of his family, which was vulnerable to the whims and predations of both Ming loyalist forces and early Qing officials. As such, modern scholars have characterised Yao Tinglin as 'an impoverished but prideful member of the lower intelligentsia.' Lynn Struve, The Ming-Qing Conflict (Ann Arbor, 1998), 247; and Kishimoto Mio, 'Rekinen ki ni miru Shinsho shakai no seikatsu' [A View of Early Qing Social Life as Seen in Record of Years Past], Shigaku zasshi 95, no. 6 (June 1986), 54.

41 Yao Tinglin, 'Linian ji' ['Record of Bygone Years'] in Qingdai riji huichao [Collectanea of Qing diaries] (Shanghai, 1982), 37-168. Yao's depiction of the Kangxi emperor's first southern tour in 1684 can be found on pages 118-121. This text was never formally published but presumably circulated in manuscript form among Yao's immediate circle of relatives, friends, and acquaintances. It is now held in the rare book section of the Shanghai Library.

42 Yao, 'Linian ji', 42 and 156.

$43 E C C P, 709-710$. Tang Bin served in the post of Jiangsu Provincial Governor for only two years (1684-1686) before he was recalled to the capital to serve as a tutor to the Heir Apparent. 
In terms of its general structure, Yao Tinglin's account closely follows that written by Magistrate Liu in the Wu County Gazetteer. Yao claims to have been 'an eye-witness to the auspicious presence of the phoenix-emperor' when the imperial procession arrived in Suzhou on 2 December 1684. According to Yao, after disembarking from the imperial boat, the Kangxi emperor:

... entered Chang Gate on horseback, crossed the large bridge, and then proceeded south to Ruiguang Temple, [where he] entered the temple gate, dismounted, burned incense, bowed three times, and left. At this time, the imperial retinue, along with the provincial governor, lieutenant-governor, and other officials, [followed] on a total of sixty to seventy horses. At Pan Gate, [the emperor] mounted the city wall, proceeded north past Xu Gate and Chang Gate. In the northwest [he] passed by Qi Gate and turned east, arriving at Lou Gate [at the northern end of Suzhou's eastern wall], where [he] descended from the city wall and was invited to enter a temporary palace which had been set up next door. ${ }^{44}$

This temporary palace was none other than Suzhou's famed Garden of the Humble Administrator (Zhuozheng yuan, a.k.a. Garden of the Unsuccessful Politician), located in the north-eastern corner of the city.

The garden was a well-known monument not only to literati values and culture, but also to the vicissitudes of Qing conquest and occupation. Originally built by a Ming censor in the early sixteenth century, the Garden of the Humble Administrator gained iconic status in 1533 when the well-known Ming literatus Wen Zhengming (1470-1559) executed an album of paintings and poems celebrating its various vistas. During the Qing conquest, however, the Garden of the Humble Administrator was occupied by a Manchu general and then sold in 1653 to Chen Zhilin $\left(1605^{-1666)}\right.$, a scion of the famed Chen lineage from Haining, Zhejiang. ${ }^{45}$ When Chen was beset by political difficulties in 1656,46 the Qing court confiscated his estate, including the Garden of the Humble Administrator which then served as the office and residence for a succession of Qing garrison commanders in the early Kangxi period. Soon after

\footnotetext{
44 Yao, 'Linian ji', 119.

45 For more on the Chen clan see Lai Huimin, Qingdai de huangquan yu shijia [Qing imperial power and great families] (Beijing, 2010), 37-75.

46 Chen Zhilin was the first in his family to surrender to the Qing and was first appointed to the metropolitan bureaucracy in 1651 . He quickly rose to the post of Grand Secretary but was cashiered in 1656 on charges of factionalism and protecting southerners. Chen spent the last decade of his life (1656-1666) in exile in Liaodong, north of the Great Wall.
} 
Chen Zhilin's death in 1666, the garden was returned to his son, who then sold it to Wang Yongning, the son-in-law of General Wu Sangui (1612-1678) a former Ming general who had aided the Manchus in their conquest of China. ${ }^{47}$ When General Wu rebelled against Qing rule in 1673, his son-in-law Wang Yongning committed suicide, whereupon the Qing state once again confiscated the Garden of the Humble Administrator. ${ }^{48}$ This long and complicated history made the garden a 'fruitful site' of symbolic negotiation and contestation. ${ }^{49}$

As we may recall, Magistrate Liu's account in the Wu County Gazetteer made note of, but did not detail or explain, the Kangxi emperor's visit to the Garden of the Humble Administrator in $1684^{50}$ In other words, Magistrate Liu effectively confirmed the veracity of this event, but left its meaning and significance open to interpretation.

Local residents in Suzhou and beyond were well aware of the garden's rather fluid symbolic status, especially in the recent past..$^{51}$ Moreover, in Yao Tinglin's eyes the Garden of the Humble Administrator was no longer a monument to the aesthetic and cultural values of Han Chinese literati, but rather a symbol of both Manchu occupation and Han Chinese collaboration. Yao described the garden as 'the residence of Wu Sangui's son-in-law, Wang efu.' His use of the Manchu term for son-in-law (efu) indicates that he considered both General $\mathrm{Wu}$ and his son-in-law to be members of the Qing imperial clan. Such views were not entirely baseless. In 1645 the Qing court had granted General Wu the title of first-degree prince of the blood (qinwang) in honour of his military contributions to the Qing cause; then in the early 1650s General Wu's eldest son (Wu Yingxiong, d. 1674) was granted a title of nobility (viscount, third-class) and allowed to marry a Manchu princess. ${ }^{52}$ As such, the Garden of the Humble Administrator might have been considered the property of the Qing imperial household when General Wu's son-in-law, Wang Yongning, purchased it from

\footnotetext{
$47 \quad$ ECCP, 877-880.

48 Ye Mengzhu, Yueshi bian (Beijing, 2007), 84; and Gu Gongxie, Danwu biji (Nanjing, 1999), 61 as cited in Wang Gang, 'Qingchu Suzhou baqi zhufang tanxi' [An analysis of the Suzhou banner garrison in the early Qing], Qingshi yanjiu, no. 2 (May 2013), 104.

Craig Clunas, Fruitful Sites: Garden Culture in Ming Dynasty China (Durham, NC, 1996), 23-59.

$50 \quad$ WXZ, juan shou, za.

51 According to one Ye Mengzhu (b. 1623), a contemporary observer and denizen of Shanghai, at the start of the Rebellion of the Three Feudatories in 1678 the Superintendent of the Suzhou-Songjiang-Changzhou circuit, Zu Zeshen, donated funds to repurchase the garden estate and converted it back into a government office (presumably his own official headquarters). Ye Mengzhu, Yueshi bian (Beijing, 2007), 84. 
the Chen family in the late-166os. However, General Wu's eventual rebellion against Qing rule (1673-1681) once again cast doubt upon the cultural and political status of this well-known garden.

According to Yao's narrative, Jiangsu Provincial Governor Tang Bin had treated the Garden of the Humble Administrator as 'the confiscated property of a traitor' and had spared no expense in renovating it to serve as the Kangxi emperor's temporary palace in $1684 .^{53}$ In the eyes of local residents, however, Governor Tang's initiative seemed to be in violation of publicly promulgated imperial orders which, again according to Yao, explicitly forbade 'the demolition of ordinary homes in order to construct temporary palaces. ${ }^{54}$

Here Yao Tinglin was most critical of Governor Tang for having reprised the historic role of Wang Yongning, the rebellious General Wu's son-in-law and the last private owner of the Garden of the Humble Administrator. If local lore is to be believed, Wang was a profligate wastrel who renovated the property as a venue for the lavish banquets which he frequently threw. The Kangxi emperor, for his part, appears to have deftly avoided any direct association with Governor Tang's reclamation of the garden under imperial auspices by deciding on the spot to spend the night in the Suzhou Silk Commissioner's quarters instead.

Here we may pause to note Yao's penchant for repeatedly drawing attention to the ethnic identity of the emperor and members of his retinue. Yao freely employed Manchu terms such as efu (son-in-law) and hafan (official), and his descriptions of the imperial procession were both martially and ethnically inflected:

On this day [2 December 1684], the officials following the imperial procession all arrived and spent the night in the vicinity of the Silk Commissioner's residence. The Zhenjiang [garrison] commander General Yang (note [in original]: This is Yang Fengxian, a Manchu) ${ }^{55}$ rode in front of the Imperial Father's horse in order to protect the imperial procession, as if he was [a scout] riding point. At this time all of the offi-

53 Yao, 'Linian ji', 119. According to Yao's description, 'all the halls and pavilions were renovated to look like the inside of a Buddhist temple.'

54 Yao, 'Linian ji', 119.

55 General Yang Fengxiang (d. 1691) was actually a Han-martial bannerman, not a Manchu, who served as the Jingkou [Zhenjiang] banner garrison commander from 1678 to 1690. Qian Shifu, ed., Qingdai zhiguan nianbiao [Tables of Qing officials] (Beijing, 1980), $2236-2242$. 
cials [following in retinue] assembled within the walls of Old Suzhou; how crowded it was! ${ }^{56}$

For Yao, however, the main problem was neither the ethnicity of the Kangxi emperor and his officials, nor the crowding and disruption associated with the bivouacking of emperor and his retinue, but rather the behaviour of local officials such as Tang Bin and the Suzhou Silk Commissioner. As Yao recounts, the latter played host to the Kangxi emperor and tried to curry imperial favour by entertaining him with opera performances by local troupes which lasted past midnight. The next morning, as the Kangxi emperor was about to set out for Tiger Hill, the Suzhou Silk Commissioner suggested that the emperor first have something to eat and once again arranged for more local opera performances which dragged on into the afternoon. In the end, the emperor and his entourage did not mount their horses and set out for Tiger Hill until much later in the day.

According to Yao Tinglin, Governor Tang Bin, not to be outdone, arranged for local commoners to kneel along the roadside and greet the imperial procession as it passed through the city. The Kangxi emperor added to the spectacle by ordering one of his high-ranking Manchu officials (again Yao uses a Chinese transliteration of the Manchu term for 'official', hafan) to allow all residents, both men and women, to come gaze upon the imperial procession. In addition, the imperial edict stated that large and small shops were to remain open and not allowed to close. The result was an extravaganza of popular enthusiasm and réclame in which commoners filled the streets and women crowded onto balconies to watch and shout 'Long live the emperor! ${ }^{57}$

As Yao tells it, the imperial procession arrived at Tiger Hill where the festivities and excitement continued unabated. The Kangxi emperor presented sacrifices in the main Buddha hall and at a shrine honouring local worthies and then enjoyed performances of local music arranged by Governor Tang Bin. The emperor then summoned his own court musicians - whom Yao describes as sixteen 'young foreigners' all of whom were 'attractive and intelligent boys, aged 15-16 sui', dressed in 'crimson court robes and red fur hats' - and ordered them to play some northern tunes for the crowds that had gathered. As Yao notes, this impromptu performance went on for two hours, until dusk. As he began to leave, the Kangxi emperor encountered another throng of onlookers at Tiger Hill's famed Thousand Person Stone Terrace. Because this crowd had not seen the earlier performance, the emperor ordered his foreign court

\footnotetext{
56 Yao, 'Linian ji', 120.

57 Yao, 'Linian ji', 120.
} 
musicians to play another set. According to Yao, the emperor himself picked up a drum and personally joined the act which lasted until the second watch (9-11 p.m.). Only then did the imperial procession leave Tiger Hill and continue on its way from Suzhou to Wuxi. ${ }^{58}$

As most critical readers both then and now would notice, a number of details in Yao Tinglin's account seem like rather fanciful embellishments, added for dramatic and narrative effect. For example, Yao included direct quotations of face-to-face conversations between the emperor and his officials in both the Garden of the Humble Administrator and the Suzhou Silk Commissioner's residence, to which he was certainly not privy. That being said, Yao's vivid and detailed descriptions of the imperial procession's passage through the city's streets as well as of the emperor's activities in the more publically accessible spaces at Tiger Hill seem more plausible, not simply because they roughly coincide with the basic outlines of the account in the Wu County Gazetteer, but also because Yao may have conceivably borne witness to such scenes in person. In the end, however, questions about the veracity and reliability of this unofficial source may be irresolvable and perhaps beside the point.

The value of Yao's unofficial account lies not in its truthfulness or empirical accuracy, but rather in its alternative and implicitly critical perspective, especially vis-à-vis officially sponsored accounts. In Yao's private narrative the Kangxi emperor is neither insulated from his surroundings nor critical of Suzhou's local customs. Nor is he in any particular rush; on the contrary, he is easily and repeatedly delayed. Furthermore, he revels in the city's raucous atmosphere and embraces various forms of popular entertainment, even attempting to impress the local populace with performances by his foreign court musicians. This depiction of a Manchu ruler who is fully immersed in an urban spectacle stands in stark contrast to the more solemn portrayals of the imperial presence found in officially sponsored sources, which suggests that the latter are not only formulaic and overly idealised, but also highly sanitised.

\section{Concluding Remarks}

In the preceding pages, I have treated the Kangxi emperor's first visit to Suzhou in late 1684 as what Marshall Sahlins has dubbed a 'structure of conjuncture' - that is, as an occasion for the 'practical realisation of cultural categories in a specific historical context, as expressed in the interested action of historic agents. ${ }^{\prime 9}$ Here the historical agents under consideration include a

\footnotetext{
58 Yao, 'Linian ji', 120.

59 Sahlins, Islands of History, xiv.
} 
range of individuals - court scribes and imperial diarists, the emperor and his ghost-writers, a county magistrate and a more distant observer-all of whom produced narrative accounts of the imperial presence in Suzhou in late 1684. These accounts are not merely descriptions of an event, but are also claims to knowledge about the imperial court and its officials, and by extension, active interpretations (and, in the case of Yao Tinglin, an implicit critique) of Qing rule.

The Kangxi emperor's varying degrees of openness and receptivity to his immediate surroundings during his first visit to Suzhou in 1684 was a common point of concern that informs each of the narratives. The authors all share an underlying assumption that their portrayals of the emperor's general disposition towards Suzhou - its residents, its scenic sites, as well as its local habits, customs, and culture-might shape broader perceptions and thus affect, positively or negatively, the legitimacy of Qing rule.

The official account in the Imperial Diaries reinforces a stereotyped image of the Kangxi emperor as a living embodiment of time-honoured virtues of diligence, benevolence, and frugality who had little reason or desire to linger in Suzhou. The imperial essay 'Note on a Southern Tour' presents a more scholarly and culturally conciliatory imperial image, but always balances expressions of cultural accommodation with acts of disavowal and distancing. Both the Imperial Diaries and 'Notes on a Southern Tour' tend towards brevity and narrative compression and studiously avoid describing any of the emperor's activities inside of Suzhou proper. In short, these courtly sources conceal as much as they reveal.

Locally produced narratives provide more information regarding the Kangxi emperor's activities within the inner precincts of Suzhou's city wall, including his personal interactions with local inhabitants. The account found in the 1691 edition of the Wu County Gazetteer reflects the efforts of local officials to balance symbolic assertions of imperial dominion over Suzhou, on the one hand, and gestures of cautious reconciliation with local residents, on the other. Here the author of this text, Magistrate Liu, acknowledged the negotiated nature of Qing rule and, in doing so, sought to reaffirm and, indeed, to discursively constitute the emperor's steadily increasing legitimacy.

Of course, not everyone was necessarily so sanguine. The unofficial narrative written by a local observer named Yao Tinglin is of great value and interest, not necessarily because it provides more direct access to what 'really' happened, but rather because it provides an alternate vantage point - that of the popular imagination - from which we might more readily register not only Yao's critical attitude towards imperially appointed provincial officials as representatives of Qing rule, but also the very real limits of official sources. In 
Yao's personal account, the Kangxi emperor appears not as a stolid paragon of imperial virtues, but rather as a highly animated and self-consciously political performer who embraced his role as a Manchu ruler at the centre of an urban spectacle. Insofar as Yao's portrayal of events might point to more widespread perceptions of both the emperor and his local agents, it stands as an important reminder of the limits of official ideology as well as of the inventiveness and historical agency of those outside the court's charmed circles of power. The diversity of narrative accounts discussed in the pages above-especially as exemplified by Yao Tinglin's personal account—might also serve to remind us that the consolidation of Qing rule was a complex and contested historical process that involved the production of knowledge by a range of actors, not just the emperor and his officials. 